\title{
Cathepsin L Inhibitors with Activity against the Liver Fluke Identified from a Focus Library of Quinoxaline 1,4-di-N-Oxide Derivatives
}

\author{
Florencia Ferraro ${ }^{1,2}{ }^{-}$, Alicia Merlino ${ }^{2,+}{ }^{,}$Jorge Gil $^{3}$, Hugo Cerecetto $^{4}{ }^{\oplus}$, Ileana Corvo ${ }^{1, *}$ and \\ Mauricio Cabrera ${ }^{1, *(1)}$ \\ 1 Laboratorio de I + D de Moléculas Bioactivas, Departamento de Ciencias Biológicas, CENUR Litoral Norte, \\ Universidad de la República, Paysandú 60000, Uruguay \\ 2 Laboratorio de Química Teórica y Computacional, Instituto de Química Biológica, Facultad de Ciencias, \\ Universidad de la República, Montevideo 11400, Uruguay \\ 3 Laboratorio de Reproducción Animal, Producción y Reproducción de Rumiantes, Departamento de Ciencias \\ Biológicas, CENUR Litoral Norte-Facultad de Veterinaria, Universidad de la República, \\ Paysandú 60000, Uruguay \\ 4 Grupo de Química Medicinal, Laboratorio de Química Orgánica \& Área de Radiofarmacia, Centro de \\ Investigaciones Nucleares, Facultad de Ciencias, Universidad de la República, Montevideo 11400, Uruguay \\ * Correspondence: ilecorvo@gmail.com (I.C.); macabrera@fcien.edu.uy (M.C.); \\ Tel.: +598-47227950 (ext. 131) (I.C. \& M.C.) \\ + Dedicated to the memory of Prof. Alicia Merlino, deceased 07/08/2018, colleague and friend.
}

Academic Editor: Athina Geronikaki

Received: 16 May 2019; Accepted: 17 June 2019; Published: 26 June 2019

check for updates

\begin{abstract}
Infections caused by Fasciola species are widely distributed in cattle and sheep causing significant economic losses, and are emerging as human zoonosis with increasing reports of human cases, especially in children in endemic areas. The current treatment is chemotherapeutic, triclabendazole being the drug of preference since it is active against all parasite stages. Due to the emergence of resistance in several countries, the discovery of new chemical entities with fasciolicidal activity is urgently needed. In our continuous search for new fasciolicide compounds, we identified and characterized six quinoxaline 1,4-di- $N$-oxide derivatives from our in-house library. We selected them from a screening of novel inhibitors against FhCL1 and FhCL3 proteases, two essential enzymes secreted by juvenile and adult flukes. We report compounds C7, C17, C18, C19, C23, and C24 with an $\mathrm{IC}_{50}$ of less than $10 \mu \mathrm{M}$ in at least one cathepsin. We studied their binding kinetics in vitro and their enzyme-ligand interactions in silico by molecular docking and molecular dynamic (MD) simulations. These compounds readily kill newly excysted juveniles in vitro and have low cytotoxicity in a Hep-G2 cell line and bovine spermatozoa. Our findings are valuable for the development of new chemotherapeutic approaches against fascioliasis, and other pathologies involving cysteine proteases.
\end{abstract}

Keywords: Fasciola hepatica; cathepsin L; quinoxaline 1,4-di-N-oxides; small molecule inhibitors; molecular docking

\section{Introduction}

Liver flukes of Fasciola species infect cattle and sheep worldwide causing important economic global losses of over US\$3 billion annually to the agricultural sector [1], and are responsible for increasing numbers of human infections, being recognized as an emerging human zoonosis by the World Health Organization. Alarmingly, reports of human cases in endemic areas of Asia, Africa, and South America appear frequently, especially in children, even considering that most human infections are thought to remain undiagnosed [2,3]. Fasciola hepatica has a complex life cycle and are adapted to 
hosts of multiple species [4], thus favoring the expansion of the parasite distribution and making it an infection that cannot be targeted for eradication. Since 1995, this is aggravated by several reports of parasite isolates resistant to triclabendazole, the drug of choice to treat humans and the only one that is effective against both the mature and juvenile forms of the parasite [5,6]. Also, despite sustained efforts, there is currently no available vaccine to prevent infection [7]. These facts highlight how important it is to design new control strategies to prevent and treat fascioliasis and find new targets for vaccines and drug development.

In this sense, cysteine proteases are key enzymes that play essential roles in the F. hepatica life cycle [8], showing functional specialization [9-11]. While cathepsin L3 and cathepsin B are highly expressed by newly excysted juveniles (NEJ) taking part in excystation and early parasite migration [12,13], a different set of enzymes are secreted by adult flukes (mainly cathepsin L1 and 2) to aid in feeding and immune modulation [14,15]. Cathepsins have been previously explored as interesting targets for antiparasitic chemotherapy in Fasciola [16,17], other helminth parasites [18,19], and several protozoa (like Trypanosomes and Plasmodium falciparum) [20-23]. Inhibitors targeting cysteine proteases have also been extensively studied as potential drugs for other diseases, since cathepsins are often found upregulated in cancer, osteoporosis, and atherosclerosis, among others. A large number of small molecule peptide-like cathepsin inhibitors have been synthesized, which include irreversible inhibitors such as epoxy succinic acid, vinyl sulfone, and acyl hydrazine derivatives and reversible ones, like cycloketones, aldehydes, and nitrile derivatives [24].

We recently identified and characterized synthetic flavonoids as non-peptide inhibitors of Fasciola hepatica cathepsin L and observed their trematocidal activity against juvenile parasites [16]. Non-peptide molecules are considered a better strategy for in vivo inhibition in order to avoid degradation by proteases. Continuing with our efforts to identify new active compounds against fascioliasis from our in-house chemical library we selected a series of twenty-eight quinoxaline 1,4-di-N-oxide derivatives in order to study their ability to inhibit essential cathepsin L enzymes from Fasciola hepatica. Most are synthetic, with only a few examples of natural ones, such as echinomycin and triostin-A. These kinds of molecules have been described as antitubercular, antimalarial, antileishmania, and antichagas, among other neglected diseases [25]. However, to the best of our knowledge, there is only one report of a quinoxaline derivative that inhibited F. hepatica thioredoxin glutathione reductase and killed NEJ in vitro [26]. The wide spectrum of activity could be attributed to the great versatility of the quinoxaline 1,4-di-N-oxide nucleus, which allows the generation of a large number of derivatives. The green chemistry methodologies available for their synthesis, which includes recyclable catalysts, microwave-assisted synthesis and water reactions, contribute to their attractiveness as drug development candidates [27]. Likewise, heterocyclic $N$-oxides have emerged as promising agents against several neglected and infectious diseases [28], and some quinoxaline derivatives have been reported as antihelminthic compounds against nematodes, cestodes, and trematodes [26,29].

In this work, we identified and characterized quinoxaline 1,4-di- $N$-oxide derivatives as novel inhibitors of the two main cathepsins secreted by juvenile and adult liver flukes. These compounds readily kill NEJ in vitro and have low cytotoxicity in a human cell line and bovine sperm. These findings open new avenues for the development of novel agents to control fluke infection and possibly other helminthic diseases.

\section{Results and Discussion}

\subsection{Screening of Quinoxaline 1,4-di-N-Oxide Derivatives as FhCL1 and FhCL3 Inhibitors}

We chose a set of twenty-eight quinoxaline 1,4-di-N-oxide derivatives with different substituents in R1-R4 (Table 1) that were tested as inhibitors of two F. hepatica cysteine proteases. In Table 1 we present the list of the assayed compounds and their chemical structures. 
Table 1. Structures of quinoxaline 1,4-di-N-oxide derivatives evaluated as inhibitors of Fasciola hepatica cathepsins L1 and L3. Compounds were evaluated at $10 \mu \mathrm{M}$ concentration, the percentage of inhibition is reported relative to the activity of the enzyme alone. The compounds with the highest inhibition are in bold. The whole structure of the compounds is given in Figure S1. The standard deviation is less than $10 \%$ for all compounds.

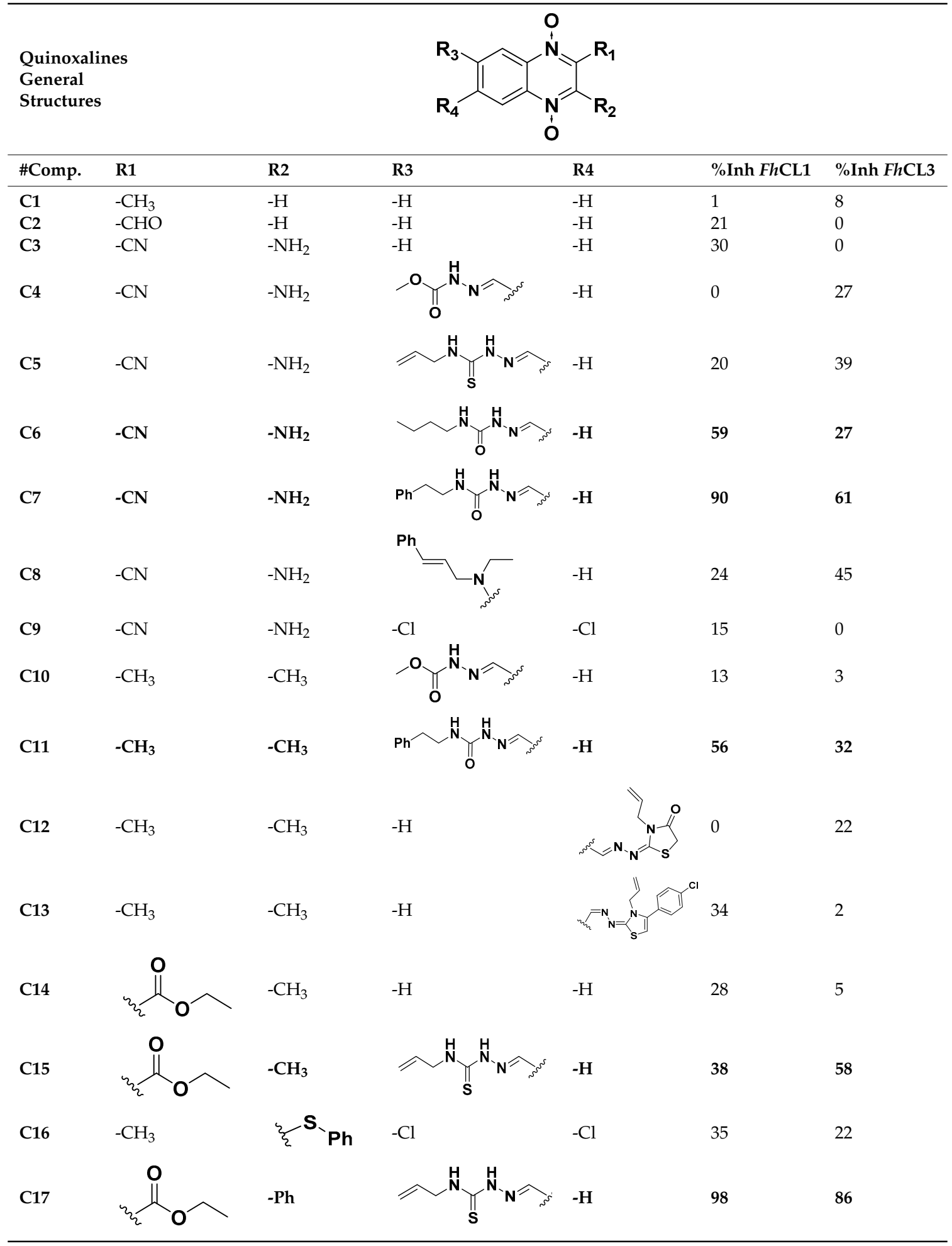


Table 1. Cont.

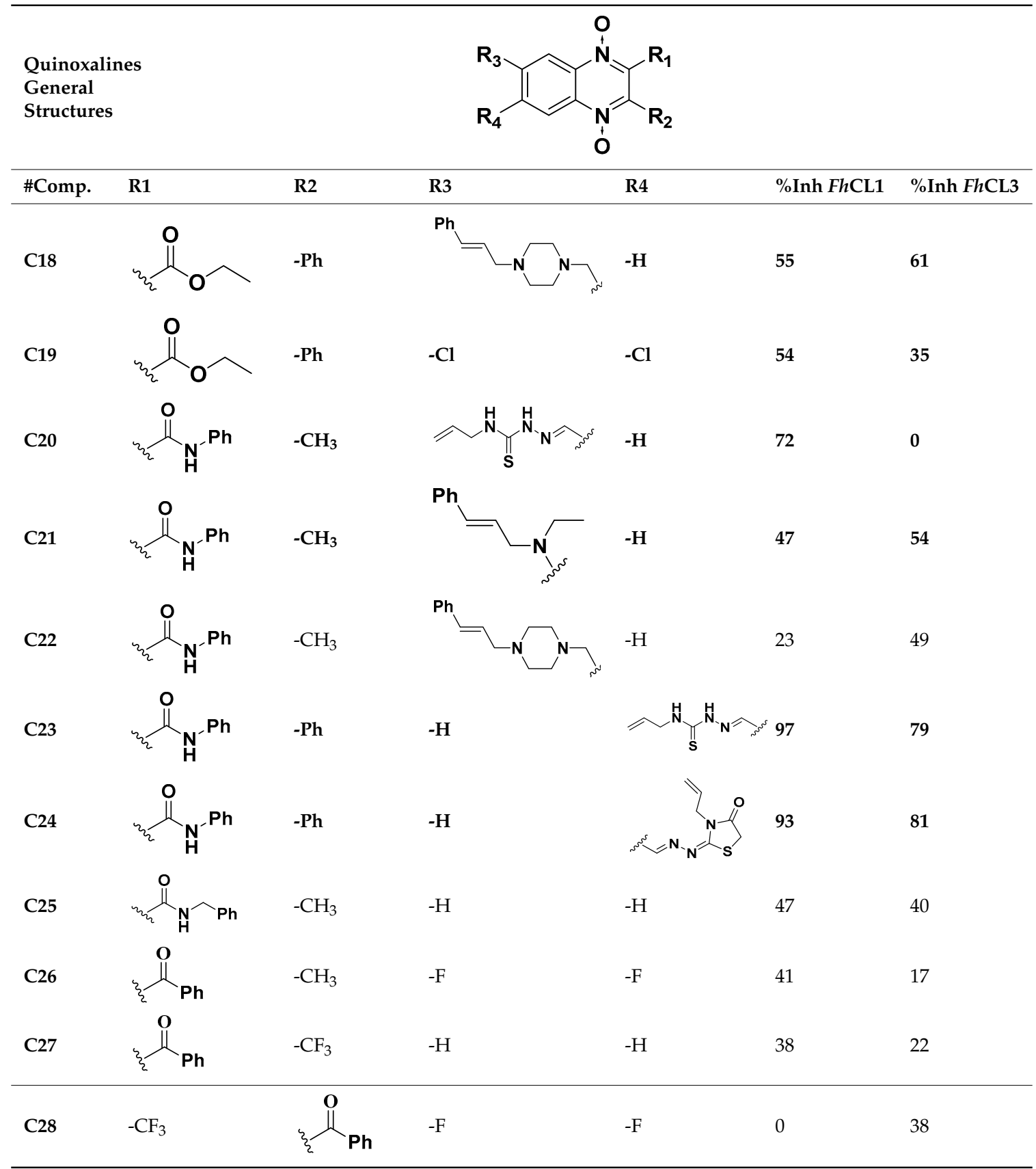

The percentage of inhibition of both enzymes for each compound is shown in Figure 1 . We found eleven derivatives that inhibited at least one of the enzymes above 50\%: C6, C7, C11, C15, C17, C18, C19, C20, C21, , and C24. Among these, three compounds stand out with an inhibition of $80 \%$ or more against both enzymes: C17, C23, and C24. 


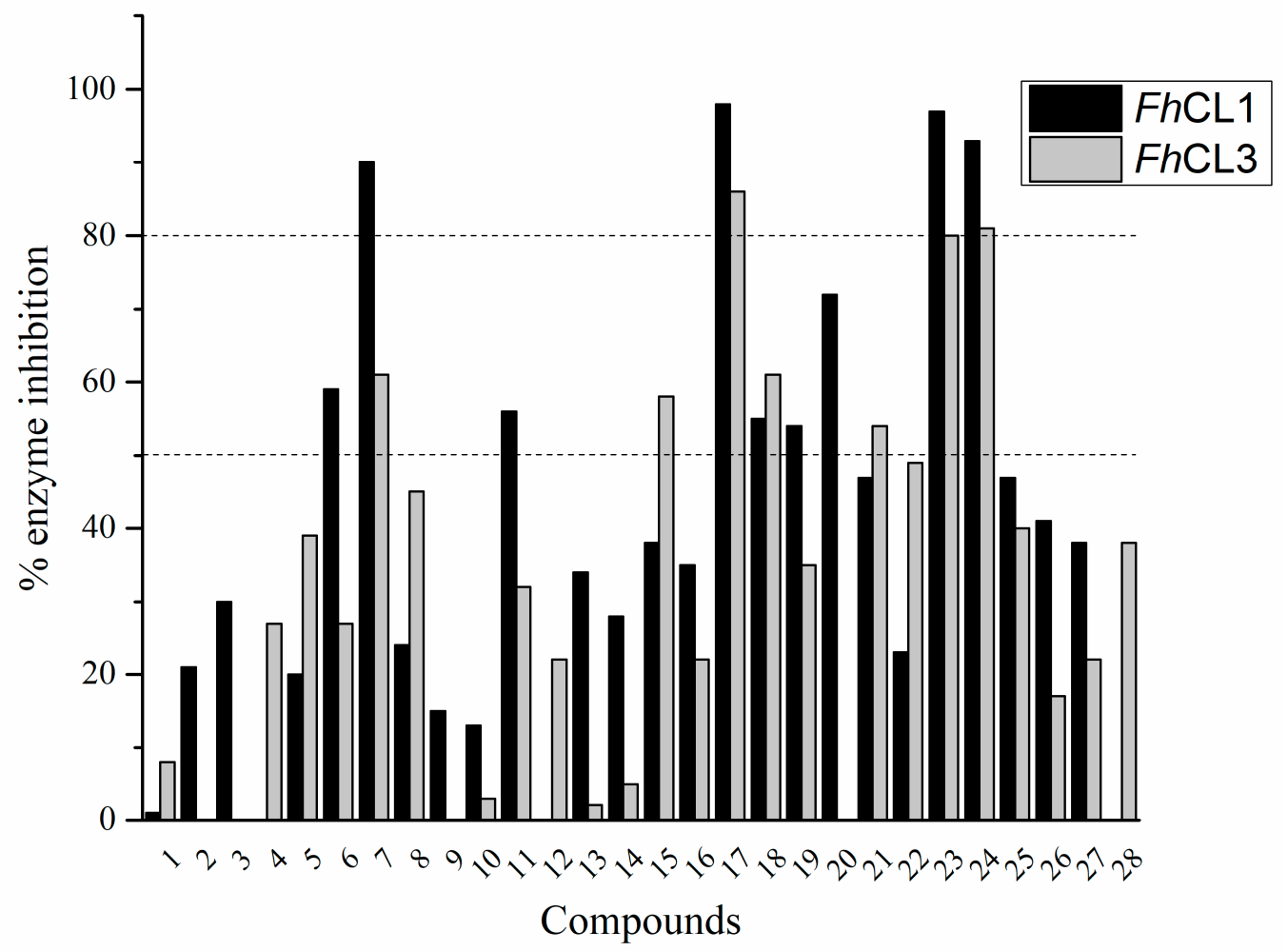

Figure 1. Screening of quinoxaline 1,4-di-N-oxide derivatives as FhCL1 and FhCL3 inhibitors. The percentage of inhibition of FhCL1 is shown in black bars and that of FhCL3 in gray bars. The standard deviation is less than $10 \%$ for all compounds.

A shared feature of the compounds with the highest inhibition percentages is the presence of an electrophilic group at R1, like an ester, amide or nitrile, that may be susceptible to nucleophilic attack by the reactive thiol at the cathepsin active site. Also, these groups have a stereoelectronic analogy with peptide bonds, the cathepsin natural substrates. The only exception is C11, which has methyl groups in R1 and R2. However, its activity might be attributed to the presence of a $\mathrm{N}$-phenethylsemicarbazone residue in R3. We observed that this substituent highly favors enzyme inhibition when comparing C6 with C7 and C10 with C11, where it improves the inhibitory activity by more than $30 \%$ in both enzymes (Table 1 and Figure 1). Strikingly, all tested quinoxaline derivatives with a phenyl substituent in $\mathrm{R} 2(\mathbf{C 1 7}, \mathbf{C 1 8}, \mathbf{C 1 9}, \mathbf{C 2 3}$, and C24) are among the best inhibitors. The positive contribution of the phenyl group in R2 to enzyme inhibition can be observed when comparing $\mathbf{C 1 7}$ and $\mathbf{C 1 5}$, where the presence of a phenyl instead of a methyl group in R2 markedly increased inhibition of both enzymes. Moreover, the three derivatives with the highest cathepsin inhibition percentages (between 79-98\%) have this substitution. Likewise, in our previous work, we found that chalcones substituted by a naphthyl group on both rings, were the best inhibitors of $F$. hepatica cathepsins [16], suggesting that the presence of bulky substituents and cyclic structures favor the inhibition of these enzymes.

Our results showed that the quinoxaline 1,4-di- $\mathrm{N}$-oxide core contributes to the observed activity in a substitution-dependent manner. The principal pharmacophoric requirements that modulate cathepsin activity for this family of compounds are summarized in the scheme in Figure 2. 


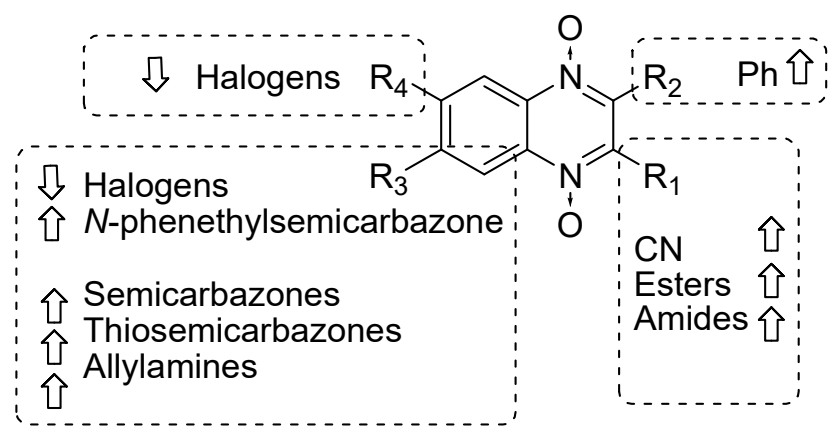

Figure 2. Schematic representation of the pharmacophoric requirements that modulate cathepsin enzyme activity. Ascending arrows indicate a substituent positively contributing to cathepsin inhibition while descending arrows indicate moieties that do not contribute to enzyme inhibition.

\subsection{Screening of Cathepsin L Inhibitors against NEJ}

We performed in vitro excystment of $F$. hepatica metacercariae to evaluate the effect of incubating the NEJ parasites with $50 \mu \mathrm{M}$ of the cathepsin L inhibitors. We evaluated the parasite movement over a time-course period as an assessment of parasite vitality, together with microscopic examination of parasite morphology (Figure 3). The incubation with C17, C18, C19, C21, and C24 resulted in a progressive decrease of parasite motility starting between 24 and $96 \mathrm{~h}$ of culture and increasing with time (Figure 3A) when clear signs of internal and tegument damage appeared (Figure 3B). After the NEJ stopped moving, a dark precipitate could be seen inside the gut, most notably in the presence of the quinoxaline C17, C19, and C24 derivatives (Figure 3B).

Among the compounds that showed high inhibition of enzyme activity, we found that those derivatives with a phenyl substituent in $\mathrm{R} 2(\mathbf{C} 17, \mathbf{C 1 8}, \mathbf{C} 19$, and $\mathbf{C 2 4})$ also possess strong fasciolicide activity in vitro, with the exception of $\mathbf{C 2 3}$ that slightly affected parasite motility. The structure of these compounds share the presence of bulky substituents in R2 and R3/R4, while the good enzyme inhibitors substituted with methyl or amino groups in these positions $(\mathbf{C 6}, \mathbf{C} 7, \mathbf{C 1 1}$, and $\mathbf{C 1 5})$ did not have activity against the parasites (see Table 1 and Figure 3). The importance of bearing a phenyl group at the R2 position for the fasciolicide activity is clearly seen if we compare $\mathrm{C} 17$ and $\mathbf{C 1 5}$ derivatives. The $\mathrm{IC}_{50}$ for our best compound $\mathrm{C} 17$ was estimated to be $25.1 \mu \mathrm{M}$ (Figure 3C).

Our results with the in vitro cultured NEJ are consistent with our previous studies of cathepsin inhibitors, where we observed a reduction in NEJ motility and parasite death when incubated with chalcones that inhibit cathepsin Ls activity [16]. Also, reports of RNA interference against Cat-L and B and an in vitro treatment of NEJ with the cathepsin L and B inhibitors E64-d and CA-074Me, described a loss of worm motility accompanied by structural damage of the parasites [30,31], and a reduction in the ability to migrate through the duodenum wall [30]. In vivo, these results might translate into an inability of the parasites to migrate through the peritoneal cavity and into the liver, thus preventing the establishment of the infection. 
A

\begin{tabular}{|c|c|c|c|c|}
\hline \multirow{2}{*}{ \#Comp. } & \multicolumn{4}{|c|}{ Motility Score } \\
\hline & $24 \mathrm{~h}$ & $48 \mathrm{~h}$ & $72 \mathrm{~h}$ & $96 \mathrm{~h}$ \\
\hline \multicolumn{5}{|l|}{ Ctrl. } \\
\hline \multicolumn{5}{|l|}{ C6 } \\
\hline \multicolumn{5}{|l|}{ C7 } \\
\hline \multicolumn{5}{|l|}{ C11 } \\
\hline \multicolumn{5}{|l|}{ C15 } \\
\hline \multicolumn{5}{|l|}{ C17 } \\
\hline \multicolumn{5}{|l|}{ C18 } \\
\hline \multicolumn{5}{|l|}{ C19 } \\
\hline \multicolumn{5}{|l|}{ C21 } \\
\hline \multicolumn{5}{|l|}{$\mathrm{C23}$} \\
\hline \multicolumn{5}{|l|}{$\mathrm{C24}$} \\
\hline & & luced motili & & \\
\hline
\end{tabular}

C

\begin{tabular}{|c|c|}
\hline \#Comp. & IC $_{\mathbf{5 0}}(\boldsymbol{\mu M})$ \\
\hline C17 & 25.1 \\
\hline
\end{tabular}

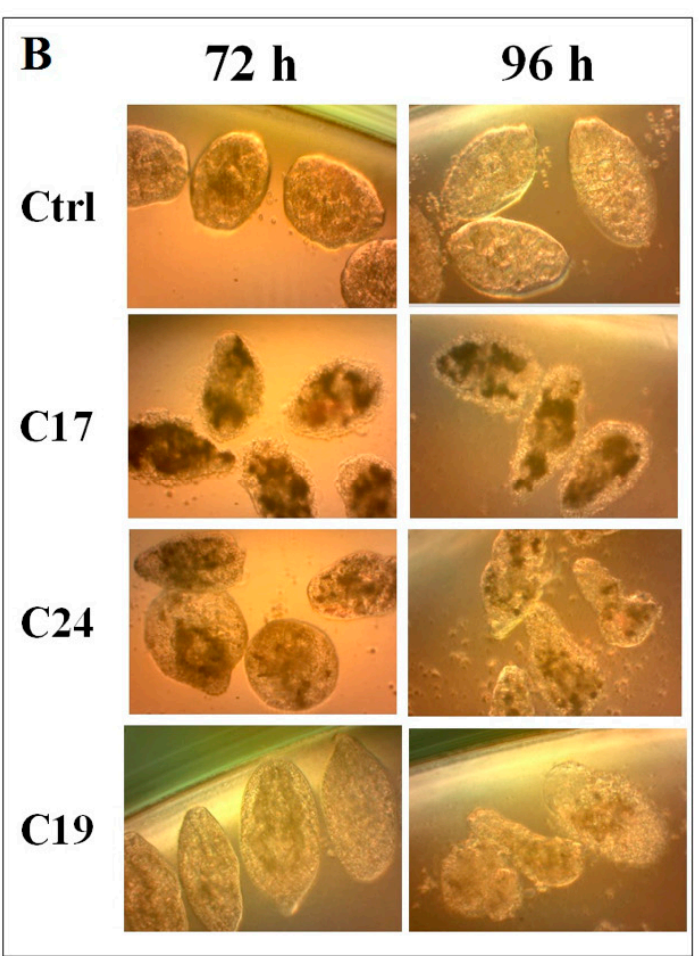

Figure 3. Effect of the cathepsin inhibitors against F. hepatica NEJ cultured in vitro. (A) Color chart showing the motility score of NEJ incubated with $50 \mu \mathrm{M}$ of compound over $96 \mathrm{~h}$. NEJ were classified in three-movement categories (taken from [32]: light gray = normal motility; gray = reduced motility (sporadic movement); black = immobile (dead). (B) Microscopic appearance of parasites incubated with $50 \mu \mathrm{M}$ of $\mathbf{C 1 7}, \mathbf{C} 24$, and $\mathbf{C} 19$ at 72 and $96 \mathrm{~h}$ treatment. Control NEJ were incubated in $0.5 \%$ DMSO.

(C) $\mathrm{IC}_{50}$ determination for the most relevant compound, $\mathrm{C} 17$, after $48 \mathrm{~h}$ of incubation with NEJ.

\subsection{Analysis of Hit Compounds}

To further characterize these molecules, we selected six hit compounds: $\mathbf{C 7}, \mathbf{C} 17, \mathbf{C} 18, \mathbf{C} 19, \mathbf{C} 23$, and C24 to determine their $\mathrm{IC}_{50}$ (Figure 4). We chose them based on the enzymatic and phenotypic screenings as they showed the highest ability to inhibit cathepsins in vitro and to impair NEJ development. We included $\mathbf{C} 7$ and $\mathbf{C} 23$ because although they did not have fasciolicidal activity, they strongly inhibited cathepsin activity.

In general, the compounds reached higher inhibition percentages with FhCL1 than FhCL3, and accordingly, the $\mathrm{IC}_{50}$ values were smaller for the former enzyme. All of the compounds had an $\mathrm{IC}_{50}$ of $10 \mu \mathrm{M}$ or less with FhCL1, while four of them had similar low values for FhCL3 (C7, C17, C18, and C24). These results are consistent with our previous observations when screening chalcones for cathepsin $\mathrm{L}$ inhibition where we found that FhCL1 activity was easier to disturb and was inhibited by a higher number of the compounds assayed when compared to FhCL3 [16]. This could be a consequence of the broader conformation of FhCL1 active site cleft that might accommodate different small molecules straightforwardly [33,34]. 


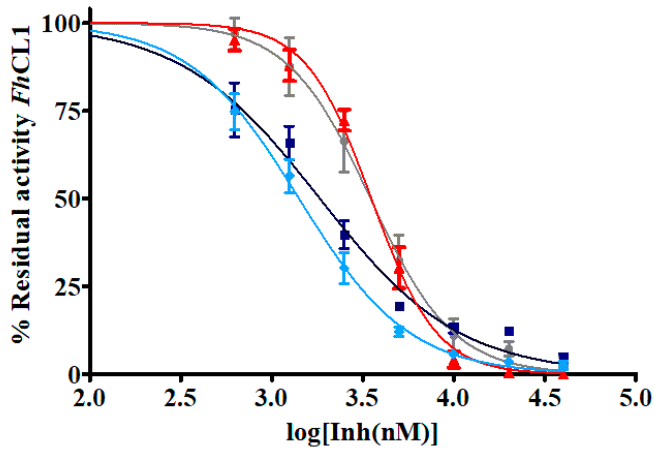

A

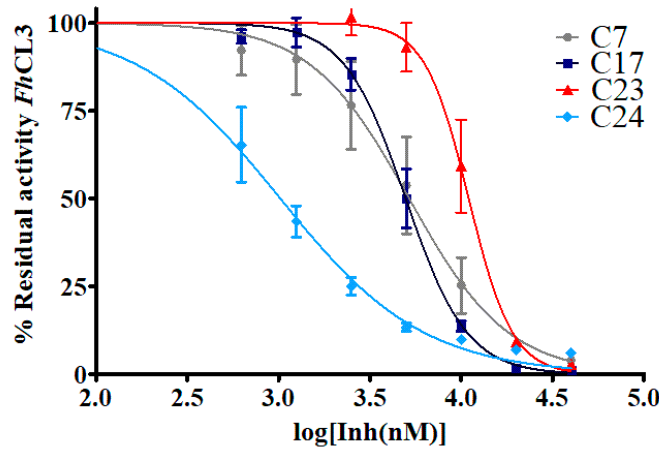

B

\begin{tabular}{ccccccc}
\hline $\mathrm{IC}_{50}(\boldsymbol{\mu M})$ & $\mathrm{C} 7$ & $\mathrm{C} 17$ & $\mathrm{C} 18$ & $\mathrm{C} 19$ & $\mathrm{C} 23$ & $\mathrm{C} 24$ \\
\hline $\boldsymbol{F h C L 1}$ & 3.5 & 1.7 & 9.0 & 5.0 & 3.0 & 1.4 \\
$\boldsymbol{F h C L 3}$ & 5.2 & 4.9 & 8.0 & $>50$ & 11 & 0.9 \\
\hline
\end{tabular}

Figure 4. The $\mathrm{IC}_{50}$ of the hit quinoxaline $1,4-$ di- $N$-oxide derivatives are shown in $\mu \mathrm{M}$. To obtain the $\mathrm{IC}_{50}$ value, the percentage of residual enzymatic activity for (A) FhCL1 and (B) FhCL3 was plotted against the logarithm of the concentration of compound $(\log [\operatorname{Inh}(n M)])$. The dose-response curves for the best inhibitors $\mathrm{C} 7, \mathrm{C} 17, \mathrm{C} 23$, and $\mathbf{C} 24$ are shown below.

\subsection{Cathepsin Inhibitors Are Slow-Binding and Interact at the Active Site Cleft}

The calculated $\mathrm{IC}_{50}$ values give an idea of the binding affinity of the compounds for the parasite enzymes (Figure 4). A retrospective study of successful drugs suggests that kinetic parameters correlate better with in vivo efficacy than binding affinity [35]. We then studied whether the extent of compounds inhibition was time-dependent. We observed that compounds show a slow-binding interaction with the enzymes, some of them showing a different behavior with each enzyme. Compounds C7, C17, and C23 required short times to inhibit FhCL1 enzyme, while C18 and C23 reached high inhibition of FhCL3 within a few minutes of incubation (Figure 5).

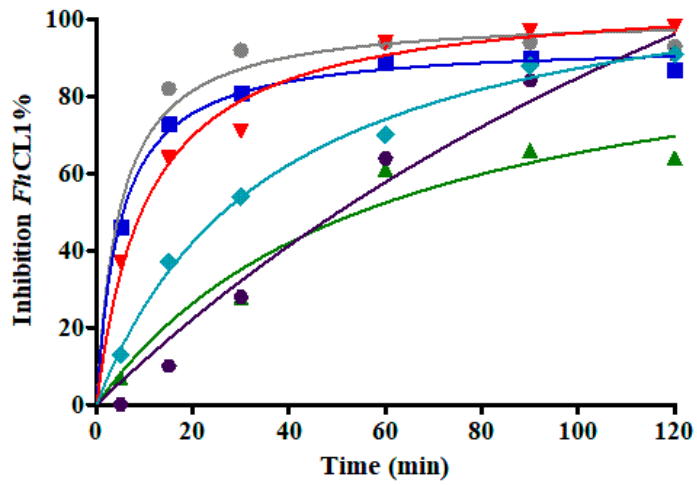

A

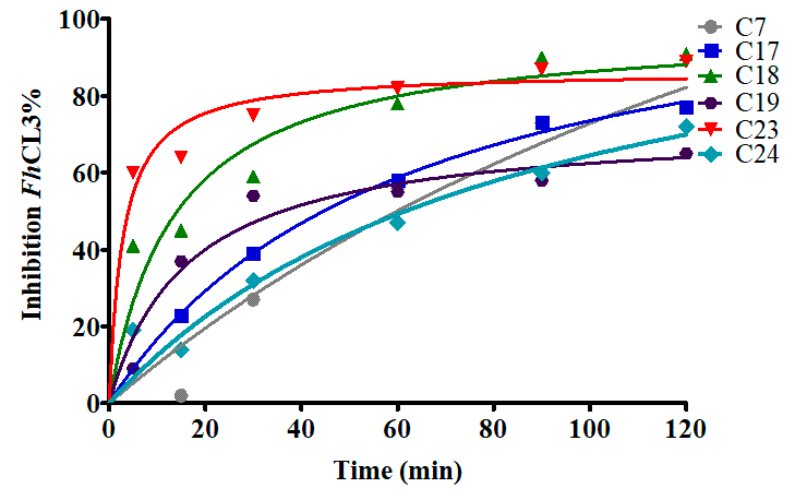

B

Figure 5. The effect of increasing the preincubation time of the compounds (at $10 \mu \mathrm{M}$ ) with the enzymes on the inhibition percentage to test for slow-binding kinetics. The enzymatic activity for (A) FhCL1 and (B) FhCL3 was measured after incubation of each enzyme with the inhibitors for different lengths of time from 5 to $120 \mathrm{~min}$.

Drug-target interactions are influenced by the conformational dynamics of the protein and the ligand, and the complex formed when they bind. Therefore, to get a better picture of the enzyme-drug complex, we performed molecular docking and molecular dynamics simulations to predict the binding site and the predominant binding interactions of these quinoxalines with cathepsins. For FhCL3, the 
most representative clusters of compounds were observed to interact deep inside the catalytic cleft (1st binding site), while in FhCL1, only compound C18 was positioned in a similar site. The other five compounds were located at a second site a little further from the $S_{2}$ and $S_{3}$ pockets but near the catalytic dyad occluding the cleft entrance (Figure 6). In any case, the position occupied by the compounds could hinder substrate entrance and accommodation along the active site, and thus, exert the observed inhibition of enzyme activity.

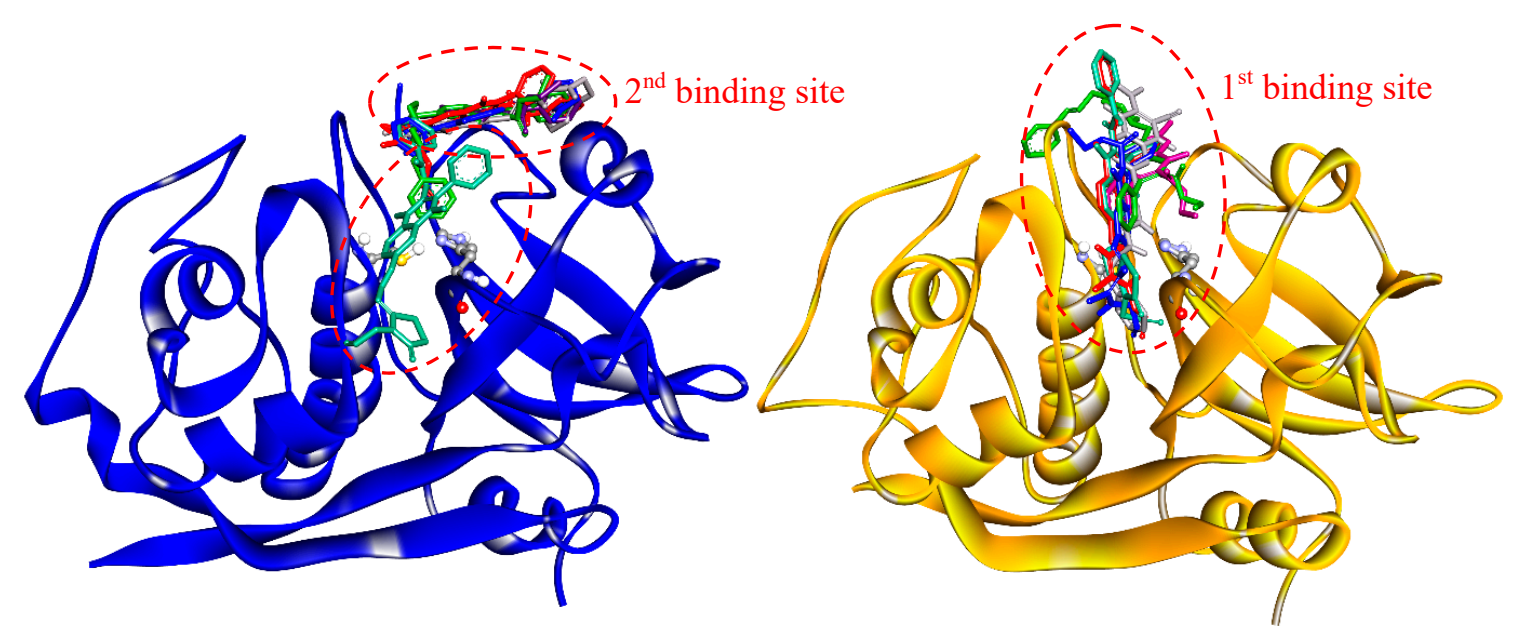

Figure 6. Binding sites of quinoxaline 1,4-di- $N$-oxide derivatives as predicted by molecular docking. Enzymes are represented in the new cartoon (FhCL1 in blue and FhCL3 in orange), the most representative clusters for the six-hit compounds are shown in sticks and the catalytic dyad in balls and sticks.

Among the hit compounds, C17 showed high enzyme inhibition in vitro and the strongest fasciolicide activity against the cultured NEJ (Figures 1 and 3). In order to obtain a more detailed view of the interactions that are established between this compound and the target proteins, we performed a molecular dynamics (MD) simulation study. To start the simulations, we employed the most populated cluster obtained for the compound in the molecular docking as an initial complex and analyzed the interaction between the enzymes and C17 during 100 ns.

For FhCL3, the ligand is positioned deep along the active site cleft and interacts with Cys 25 of the catalytic dyad and with the $\mathrm{S}_{2}$ and $\mathrm{S}_{3}$ pockets, which are involved in substrate accommodation and catalysis (Figure 7) $[17,33,36]$. Several hydrophobic interactions are seen between the thiosemicarbazone and Gly 66, Met 68, Ala 133, Val 157, and Ala 160 from the $S_{2}$ and $S_{3}$ pockets. Also, the compound establishes a hydrogen bond and a pi interaction with $\operatorname{Trp} 177$, and an electrostatic interaction (pi-cation) with Trp 67 (Figure 7, right panels). In particular, this residue has proven to be crucial for enzyme activity [33]. In the MD simulation with FhCL1, C17 is placed closer to the catalytic dyad compared to the docking site. Its interaction with FhCL1 occurs in a different orientation compared to FhCL3, so that the ester and phenyl groups at R1 and R2 are near the catalytic dyad and not the thiosemicarbazone. Hydrophobic interactions are seen between the compound and Val 137, located near the FhCL1 S pocket. Moreover, hydrophobic contacts and a hydrogen bond are established with residues that belong to the oxyanion hole, Gln 19, $\operatorname{Trp} 177$, and $\operatorname{Trp} 181$ (Figure 7, left panels), where the transition state of the reaction is stabilized [37]. The occlusion of the oxyanion hole would hinder the proper positioning of the substrate for catalysis. We observe that hydrophobic stacking interactions contribute significantly to the affinity of the compound for parasite cathepsins. Accordingly, the hit compounds share hydrophobic substituents in more than one position.

The disturbing of the protein structure upon substrate binding is also reflected by the changes in the frequency of intra-molecular protein hydrogen bonds that vary with the presence of C17. Many hydrogen bonds change their occupancy in the presence of the compound, for FhCL3 this is 
particularly seen in the residues around the active site pockets (Figure S2). In FhCL1, the configuration of the glycine-rich loop 1 (residues 52-67) that edges the $S_{3}$ pocket is greatly modified, even though $\mathrm{C} 17$ does not make direct contact with this region (Figure S2). Conformational changes around the catalytic cleft contribute to the interference with the enzyme's activity [38].
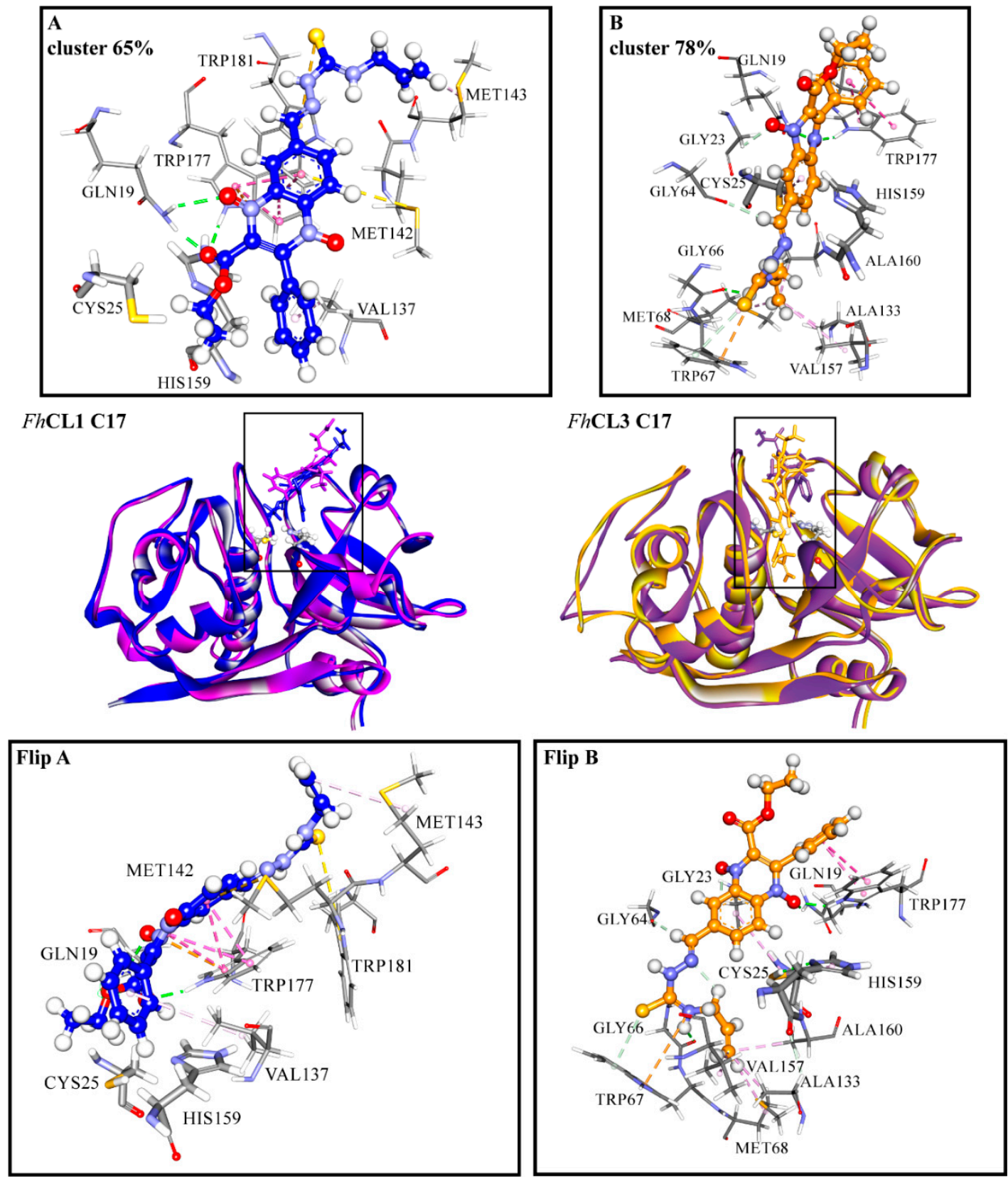

Figure 7. (A) FhCL1 and (B) FhCL3 interactions with C17 from MD simulations. In the middle is shown the most representative cluster structure obtained in the MD simulations for each enzyme-ligand complex in blue for FhCL1 and orange for FhCL3, and the most representative cluster obtained by the docking of both enzymes in purple. We zoomed in the region of the enzyme-ligand interaction for the most representative cluster to show the enzyme (sticks) and ligand (scaled ball and sticks) residues involved and the interaction types in dashed lines (green: hydrogen bonds, pink: hydrophobic interactions, yellow: pi-sulfur, orange: pi-cation). In the lower panels the complex with C17 for FhCL1(Flip A) and FhCL3 (Flip B) is seen from another perspective. The percentages correspond to the frequency obtained by the clustering of all the frames in each of the MD simulations. Residues are numbered according to papain (PDB code: 9PAP). 


\subsection{Selectivity Assessment against Human Cathepsin L}

Since parasitic cathepsins have structural homology with mammalian lysosomal cathepsins (the parasite hosts), we should not be surprised if the hit compounds affect to some extent the activity of the human enzyme as well. However, an interesting finding was that all of the tested compounds had a stronger inhibitory activity for the parasite enzymes, thus reducing the probability of unwanted off-target effects. For C17, the compound that most readily killed the NEJ, the selectivity index for the parasite enzymes over the human cathepsin was 9.3 and 2.6 for FhCL1 and FhCL3, respectively, demonstrating higher efficiency to inhibit the parasite enzymes (Figure 8).

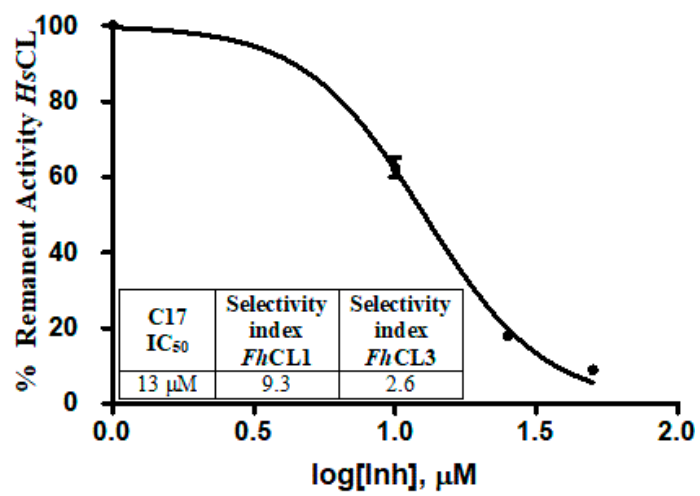

\begin{tabular}{cccc}
\hline Comp. (10 $\boldsymbol{\mu M})$ & HsCL inhib.\% & FhCL1 inhib.\% & FhCL3 inhib. $\%$ \\
\hline C7 & 41 & 90 & 61 \\
C17 & 37 & 98 & 86 \\
C18 & 25 & 55 & 61 \\
C19 & 0 & 54 & 35 \\
C23 & 57 & 97 & 79 \\
C24 & ND & 93 & 81 \\
\hline
\end{tabular}

Figure 8. The table shows the comparison of the inhibition percentage of each compound at $10 \mu \mathrm{M}$ for human cathepsin L (HsCL) and the Fasciola hepatica enzymes. The standard deviation is less than $10 \%$ for each compound. In the graphic, a dose-response curve for $\mathrm{C} 17$ was performed, and the $\mathrm{IC}_{50}$ and selectivity index for the parasite enzymes were calculated.

If we compare the subsite configuration of the human and parasite enzymes, there are many residues that differ between them and particularly at the $S_{2}$ and $S_{3}$ pockets (Table 2), that might explain the differences we observed in the inhibition of the enzymes. Most of the residues involved in the interactions between FhCL3 and C17 vary between the enzymes (64, 67, 157, and 160). Also, residue 205 located at the bottom of the $\mathrm{S}_{2}$ pocket is Ala for HsCL, while Val and Leu are found in Fasciola cathepsins, contributing to shape a wider site as compared to the parasite enzymes. The nature of residue 205 had proven to determine the specificity of the human cathepsin $\mathrm{L}$ and $\mathrm{K}$ for short peptide substrates and small molecule inhibitors [39]. As for FhCL1, even though the oxyanion configuration is conserved between the three enzymes, the other residues interacting with FhCL1 are variable in HsCL. While FhCL1 has Val at residue 137 and Met at residues 142 and 143, HsCL has Gly, Leu, and Phe, respectively (Table 2). 
Table 2. Comparing the residues present in FhCL1 (blue) and FhCL3 (orange) that interact with compound $\mathbf{C 1 7}$ between the F. hepatica enzymes and the HsCL (PDB code: 1MHW). Residues are numbered according to papain (PDB code: 9PAP) as they appear in Figure 7, and the number corresponding to each enzyme is shown in superscripts. We indicated above if the residues belonged to the subsites.

\begin{tabular}{lcccccccccc}
\hline Enzyme & & S3 & \multicolumn{3}{c}{ S2/S3 } & \multicolumn{3}{c}{ S2 } \\
\hline Papain\# & $\mathbf{6 1}$ & 64 & 66 & 67 & 137 & 142 & 143 & 157 & 160 & $\mathbf{2 0 5}$ \\
FhCL1 & Asn $^{64}$ & Gly $^{67}$ & Gly $^{69}$ & Leu $^{70}$ & Val $^{139}$ & Met $^{144}$ & Met $^{145}$ & Val $^{161}$ & Ala $^{164}$ & Leu $^{\text {210 }}$ \\
FhCL3 & His $^{64}$ & Gly $^{67}$ & Gly $^{69}$ & Trp $^{70}$ & Ala $^{139}$ & Tyr $^{144}$ & Met $^{145}$ & Thr $^{161}$ & Ala $^{164}$ & Val $^{210}$ \\
HsCL & Glu $^{63}$ & Asn $^{66}$ & Gly $^{68}$ & Leu $^{69}$ & Gly $^{139}$ & Leu $^{144}$ & Phe $^{145}$ & Met $^{161}$ & Gly $^{164}$ & Ala $^{214}$ \\
\hline
\end{tabular}

\subsection{Cytotoxicity Evaluation in Bovine Sperm and a Human Cell Line}

We evaluated the cytotoxicity of the compounds in two cell models, assessing if they impair the viability of bovine spermatozoa and the human cell line HepG2. None of the compounds affected the sperm motility, and all of them have an $\mathrm{IC}_{50}$ for HepG2 between 4-50 $\mu \mathrm{M}$ (Table 3). For the HepG2 cells, the $\mathrm{IC}_{50}$ values for the active compounds are in the same order of magnitude of triclabendazole whose $\mathrm{IC}_{50}$ was $32 \mu \mathrm{M}$. This is the drug of reference to treating human infections and the only one that is effective in killing the juvenile parasites [5].

Table 3. Cytotoxicity assays in the human cell line HepG2 and bovine spermatozoa. For the HepG2 cell line, the $\mathrm{IC}_{50}$ was calculated for each compound. In bovine spermatozoa, compounds were tested at a fixed dose of $50 \mu \mathrm{M}$. Sperm motility was calculated relative to that of the control sperm (incubated with the vehicle). We included the drug of reference, triclabendazole, to test its cytotoxicity with both cell types.

\begin{tabular}{ccc}
\hline Comp\# & HepG2 IC $_{\mathbf{5 0}}(\boldsymbol{\mu M})$ & Sperm Motility RTC * $(\mathbf{5 0} \boldsymbol{\mu M})$ \\
\hline C17 & $48 \pm 0.3$ & $81 \pm 3$ \\
\hline C18 & $<6.2$ & $82 \pm 2$ \\
\hline C23 & $12 \pm 0.2$ & $82 \pm 1$ \\
\hline C24 & $16 \pm 0.1$ & $82 \pm 1$ \\
\hline TCBZ & $32 \pm 0.2$ & $88 \pm 1$ \\
\hline \multicolumn{3}{c}{}
\end{tabular}

\section{Conclusions}

In this work, we performed a screening of twenty-eight quinoxaline 1,4-di- $N$-oxide derivatives with different substituents at R1-R4 to assess their ability to inhibit two Fasciola hepatica cathepsin Ls that take part in essential parasite processes. We found that those derivatives with a phenyl group at R2 and bulky substituents in R3/R4 potently inhibit both cathepsins and have strong fasciolicide activity over NEJ. The hit compounds interact in a slow-binding fashion with the enzymes in two different sites along the active site cleft through hydrogen bonds and hydrophobic interactions with functional enzyme residues at the oxyanion hole, catalytic dyad, and substrate binding subsites. The variability found at these sites among the human and parasitic cathepsin L might account for the higher inhibition attained against the F. hepatica enzymes. Interestingly, none of the compounds was toxic to bovine spermatozoa and the cytotoxicity level was similar to that of triclabendazole, the drug currently used for animal and human treatment. Our results will contribute towards the design of new drugs against cysteine proteases for the treatment of fascioliasis. 


\section{Materials and Methods}

\subsection{Production of Recombinant FhCL1 and FhCL3}

FhCL1 and FhCL3 recombinant enzymes were expressed in the yeast Hansenula polymorpha as previously described [12,33]. Briefly, yeast transformants were cultured in $500 \mathrm{~mL}$ YEPD broth (1\% glucose, $1 \%$ tryptone, $1 \%$ yeast extract) at $37{ }^{\circ} \mathrm{C}$ to an OD600 of $2-6$, harvested by centrifugation at $3000 \times g$ for $10 \mathrm{~min}$ and induced by resuspending in $50 \mathrm{~mL}$ of buffered minimal media $(0.67 \%$ yeast nitrogen base; $0.1 \mathrm{M}$ phosphate buffer $\mathrm{pH} 6.0 ; 1 \%$ methanol) for $36 \mathrm{~h}$ at $30^{\circ} \mathrm{C}$. Recombinant pro-peptidases were secreted to the culture media and recovered by a 20-30-fold concentration of culture supernatants by ultrafiltration with a $10 \mathrm{kDa}$ cut-off membrane. The proenzymes were autocatalytically activated to the mature form by incubation for $2 \mathrm{~h}$ at $37^{\circ} \mathrm{C}$ in $0.1 \mathrm{M}$ sodium citrate buffer (pH 5.0) with $2 \mathrm{mM}$ dithiothreitol (DTT) and $2.5 \mathrm{mM}$ EDTA, dialyzed against PBS pH 7.3, and stored in aliquots at $-20^{\circ} \mathrm{C}$ until used. The concentration of active enzyme was determined by titration against the cysteine protease inhibitor E-64c.

\subsection{FhCL1 and FhCL3 Inhibition Screening}

Each compound was completely dissolved in dimethylsulfoxide (DMSO) to a concentration of $10 \mathrm{mM}$ to prepare the stock solutions. To evaluate the inhibition of FhCL1 and FhCL3 by quinoxaline 1,4-di- $N$-oxide derivatives, nanomolar concentrations of each enzyme was incubated with compounds at $10 \mu \mathrm{M}$. Briefly, each enzyme and compound were preincubated $20 \mathrm{~min}$ in a 96-well plate in $0.1 \mathrm{M}$ sodium phosphate buffer $\mathrm{pH}$ 6, $1 \mathrm{mM}$ DTT, and $1 \mathrm{mM}$ EDTA at room temperature. The reaction was initiated by adding $20 \mu \mathrm{M}$ of substrate and enzyme activity was measured by the increase in aminomethyl coumarin (AMC) fluorescence as peptide substrates were hydrolyzed (Z-VLK-AMC for FhCL1 and Tos-GPR-AMC for FhCL3), at an excitation wavelength of $340 \mathrm{~nm}$ and emission wavelength of $440 \mathrm{~nm}$ using a spectrofluorometer (Varioskan Thermo, Waltham, MA, USA). Enzyme activity was expressed as RFU/s (relative fluorescence units of AMC released per second). Each compound was tested in triplicate. A control reaction without enzymes was performed to check for the occurrence of non-catalyzed reactions between substrates and inhibitors and a spectrum from 300 to $450 \mathrm{~nm}$ wavelength was done for each quinoxaline 1,4-di- $N$-oxide derivative to verify that none of them had optical activity in the measurement range. The percentage of enzyme inhibition was calculated as $100-\left(v_{i} / v_{0}\right) \times 100$, where $v_{i}$ and $v_{o}$ correspond to the initial rate of AMC fluorescence increase $(R F U / s)$ with and without inhibitor, respectively.

\subsection{In Vitro Culture of NEJ and Treatment with the Best Inhibitors}

F. hepatica metacercariae were acquired from Instituto Miguel C. Rubino (DILAVE, MGAP, Uruguay). NEJ were obtained by in vitro excystement as previously described with minor modifications [40]. Briefly, metacercariae were incubated with 1\% sodium hypochlorite for 5 min at room temperature to remove the outer cyst wall and then washed several times with PBS. Metacercariae activation was carried out in a medium prepared by mixing equal volumes of solution $\mathrm{A}(0.4 \%$ sodium taurocholate, $120 \mathrm{mM} \mathrm{NaHCO}, 140 \mathrm{mM} \mathrm{NaCl}, \mathrm{pH} 8.0)$ and solution $\mathrm{B}(50 \mathrm{mM} \mathrm{HCl}$ and $33 \mathrm{mM}$ L-cysteine), and incubating at $39^{\circ} \mathrm{C}$ until the NEJ begin to emerge (around 3-4 h). A $100 \mu \mathrm{m}$ filter was used to retain the cyst wall. Collected NEJ were washed three times with RPMI-1640 supplemented with $200 \mathrm{U} / \mathrm{mL}$ Penicillin G sulfate, $200 \mathrm{mg} / \mathrm{mL}$ streptomycin sulfate, $500 \mathrm{ng} / \mathrm{mL}$ amphotericin B, $10 \mathrm{mM}$ HEPES, counted and divided into groups of around 20 parasites that were transferred to 96 wells in tissue culture plates. Parasites were maintained at $37^{\circ} \mathrm{C}, 5 \% \mathrm{CO}_{2}$ in modified Basch's medium [41]. At day 1 , each tested compound was added at a concentration of $50 \mu \mathrm{M}$ in $0.5 \%$ DMSO. Also, $0.5 \%$ of DMSO was added to the control groups. Each condition was tested in duplicate. NEJ behavior was monitored under a light microscope (Olympus BX41, Hamburg, Germany), every day each well was recorded for a minute in order to assess parasite motility and registered using the following score: 
3-normally active; 2-reduced activity (sporadic movement); 1—immotile (dead, adapted from [32]). Control parasites were maintained in culture for seven days.

\subsection{Characterization of the Best Inhibitors}

\subsection{1. $\mathrm{IC}_{50}$, Time-Dependence of Inhibition, and HsCL Testing}

To calculate the $\mathrm{IC}_{50}$ values, compounds were incubated with each enzyme at seven different concentrations; $0.625,1.25,2.5,5,10,20$, and $40 \mu \mathrm{M}$. Then, the enzyme activity was measured in a 96-well plate as described before. We plotted initial rates (RFU/s) versus $\log _{10}$ of inhibitor concentrations and obtained the $\mathrm{IC}_{50}$ values by fitting the data to a sigmoid curve. We also carried out slow-binding assays to evaluate the time-dependence of the inhibition. Each compound was incubated at $10 \mu \mathrm{M}$ with the enzyme for increasing lengths of time; 3 to $120 \mathrm{~min}$ and the percentage of inhibition at each time point was determined as described before. We calculated the inhibition percentage of the leader compounds at $10 \mu \mathrm{M}$ for $\mathrm{HsCL}$. The enzyme was preincubated for $20 \mathrm{~min}$ with the compounds and the activity was measured in a 96-well plate in $400 \mathrm{mM}$ sodium acetate, $\mathrm{pH}$ 5.5, with $4 \mathrm{mM}$ EDTA, $8 \mathrm{mM}$ DTT, and $20 \mu \mathrm{M}$ of substrate Z-VLK-AMC. The percentage of enzyme inhibition was calculated as described for FhCL1 and FhCL3. We determined the $\mathrm{IC}_{50}$ value for C17 against $H s C L$ by incubating the enzyme with four different concentrations of the compound $0,10,25$, and $50 \mu \mathrm{M}$ and measuring the activity as described before. We plotted initial rates (RFU/s) versus $\log _{10}$ of inhibitor concentration and obtained the $\mathrm{IC}_{50}$ value by fitting the data to a sigmoid curve.

\subsubsection{Ligand-Protein Molecular Docking to Predict the Binding Site into FhCL1 and FhCL3}

Preparation of Protein Structures

FhCL1 and FhCL3 structures, previously obtained by homology modeling, were used [33,42]. In order to improve the accuracy of the structures for molecular docking, MD simulations were performed using the pmemd module implemented in the AMBER16 package [43], with the ff14SB force field [44]. Hydrogen atoms and sodium ions (to neutralize charge) were added to each protein with the leap utility. Each system was placed in a truncated octahedral box of TIP3P explicit water [45], and extended $10 \AA$ outside the protein on all sides. The structures of FhCL1 and FhCL3 were treated as follows: (a) water and counterions were relaxed to minimize energy during 2500 steps (500 steepest descent steps, SD, and 2000 conjugate gradient steps, CG) with the protein restrained with a force constant of $500 \mathrm{kcal} / \mathrm{mol} \AA 2$; (b) the system was minimized without restraints during 20,000 steps (5000 SD and 15,000 CG). The long-range electrostatic interactions were considered using the particle-mesh Ewald (PME) method [46] and the non-bonded interactions cut-off of $10 \AA$ was used. After minimization, each system was gradually heated in an NVT ensemble from 0 to $300 \mathrm{~K}$ over 100 ps using the Berendsen coupling algorithm [47]. This procedure was followed by $100 \mathrm{~ns}$ of NPT simulations at $300 \mathrm{~K}$ and $1 \mathrm{~atm}$ pressure using the Langevin dynamics algorithm [48]. All bonds involving hydrogen atoms were constrained using the SHAKE algorithm [49]. The equations of motion were integrated with a time step of $2.0 \mathrm{fs}$ and coordinates of the systems were saved every $2 \mathrm{ps}$. Representative structures of FhCL1 and FhCL3 from the last 100 ns of the trajectories were obtained through cluster analysis using the average-linkage algorithm [50] and used for subsequent docking calculations. Clustering, root mean square deviation (RMSD), root mean square fluctuation (RMSF) and hydrogen bond analysis were performed using the cpptraj module in AmberTools16. For trajectory visualization, the Visual Molecular Dynamics (VMD) program was used [51].

Preparation of Ligand Structures

Compounds C1-C28 (structures shown in Figure S1) were fully optimized at the $\omega \mathrm{B} 97 \mathrm{XD} /$ $6-31 G(d, p)$ level $[52,53]$ in water using the integral equation formalism polarizable continuum model (IEF-PCM) [54] with the Bondi atomic radii and ultrafine grid. The nature of the optimized structures 
as stable species was inspected by checking the eigenvalues of the analytic Hessian matrix, calculated at the same level of theory, to be positive in all the cases. All these calculations were performed using the Gaussian09 software (Wallingford, CT, UK) [55].

Ligand-Protein Molecular Docking

Flexible-ligand docking was performed using a grid box of $126 \times 126 \times 126$ points with a grid spacing of $0.45 \AA$ in order to cover the entire protein surface (blind docking). The grid box was centered on the macromolecule. The results differing by less than $2.0 \AA$ in the root-square deviation were grouped in the same cluster. The conformation with the lowest binding energy was chosen from the most populated cluster, and the corresponding ligand-protein complex was used for further MD studies. All docking calculations were done with the AutoDock 4.2 [56] software package using the Lamarckian genetic algorithm. A population size of 150 individuals and $2.5 \times 10^{6}$ energy evaluations were used for 100 search runs.

\subsubsection{Ligand-Protein Molecular Dynamics MD Simulations}

Ligand-protein molecular dynamics MD simulations of the five reversible compounds with the highest $\mathrm{IC}_{50}$ values were performed with FhCL1 and FhCL3 as described above using the GAFF [57] force field for the ligand. RESP partial charges [58] for the compounds were derived using the Gaussian09 at the HF/6-31G level and the antechamber module in AMBER16 was employed to obtain the force field parameters. One-hundred nanoseconds of productive MD were simulated and coordinates of the systems were saved every 100 ps.

\subsection{Cytotoxicity Assay on the HepG2 Cell Line and Bovine Spermatozoa}

Cytotoxicity studies on the HepG2 cell line. Cells: $1.5 \times 10^{4}$ cells per 96 -well plate were cultured in $225 \mu \mathrm{L}$ of DMEM medium, supplemented with L-glutamine (1\%), penicillin/streptomycin (1\%), and $10 \%(v / v)$ fetal bovine serum (FBS). The cultures were maintained at $37^{\circ} \mathrm{C}$ and $5 \% \mathrm{CO}_{2}$ for $48 \mathrm{~h}$. Treatment: Compound solutions were prepared just before dosing. Stock solutions, $1 \mathrm{mM}$, were prepared in 100\% DMSO (Aldrich, Saint Louis, MO, USA) and $25 \mu \mathrm{L}$ of adequate dilution was added to each well $24 \mathrm{~h}$ after plating the cells. For each compound, a dose-response curve was done with five different compound concentrations: $6.25,12.5,25,50$, and $100 \mu \mathrm{M}$ (treated cells, T). No effect on cell growth was observed by the presence of $0.5 \%$ DMSO in the culture media (control cells, C). Cells were incubated with the compounds for $24 \mathrm{~h}$ at $37^{\circ} \mathrm{C}$ in $5 \% \mathrm{CO}_{2}$ atmosphere, then the medium was discarded and the cells were washed with PBS. The cells were then fixed with $50 \mu \mathrm{L}$ of TCA (50\%) and $200 \mu \mathrm{L}$ of culture medium (without FBS) for $1 \mathrm{~h}$ at $4{ }^{\circ} \mathrm{C}$. Then the cells were washed with purified water and treated with Sulforhodamin B (0.4\% wt/vol in 1\% acetic acid) for $10 \mathrm{~min}$ at room temperature. The plates were then washed with $1 \%$ acetic acid and dried overnight. Finally, $100 \mu \mathrm{L}$ of Tris buffer $(\mathrm{pH}=10.0)$ was added and absorbance read at $540 \mathrm{~nm}$. Data calculations: The assays were done in four replicates. At the end of the experiment, the cell survival percentage (SP) was calculated for each compound as $(\mathrm{T} / \mathrm{C}) \times 100$. To determine the $\mathrm{IC}_{50}$, the SP of cells at each compound concentration was plotted and the data were fitted to a sigmoid curve. The standard error was not greater than $10 \%$ for any condition. For the cytotoxicity assay with bovine spermatozoa, semen samples were obtained from a healthy fertile Hereford bull and kept frozen in $0.5 \mathrm{~mL}$ straws (extended in Andromed, Minitube, Tiefenbach, Germany) under liquid nitrogen until use. The semen used belonged to a single freezing batch that was obtained during a regular collection schedule with an artificial vagina. Samples from three straws were thawed and a sperm pool was prepared in PBS at a concentration of 80 million spermatozoa per $\mathrm{ml}$. Then, $50 \mu \mathrm{L}$ of this pool was carefully mixed with $50 \mu \mathrm{L}$ of each compound to be tested at a concentration of $50 \mu \mathrm{M}$ or $1 \%$ DMSO in control experiments. Each compound was assayed in triplicate in 96-well plates and controls were assayed in triplicate. Plates were incubated at $37^{\circ} \mathrm{C}$ for $1 \mathrm{~h}$ with moderate shaking. The motility analysis was carried out using a CASA (Computer Assisted Semen Analyzer) system Androvision (Minitube, Tiefenbach, Germany) with an Olympus 
BX 41 microscope (Olympus, Japan) equipped with a warm-stage at $37^{\circ} \mathrm{C}$. Each sample $(10 \mu \mathrm{L})$ was placed onto a Makler Counting Chamber (depth $10 \mu \mathrm{m}$, Sefi-Medical Instruments, Haifa, Israel) and the following parameters were evaluated: percentage of total motile spermatozoa (motility $>5 \mu \mathrm{m} / \mathrm{s}$ ) and velocity curved line (VCL $>24 \mu \mathrm{m} / \mathrm{s}$ ). At least 400 spermatozoa were analyzed from each sample from at least four microscope fields.

Supplementary Materials: The following are available online at http://www.mdpi.com/1420-3049/24/13/2348/s1, Figure S1 and S2.

Author Contributions: I.C., M.C., A.M. and F.F. conceived and designed the experiments; I.C., M.C., F.F. and J.G. performed the experiments; I.C., M.C. and F.F. analysed the data; I.C., M.C., A.M., J.G. and H.C. contributed reagents/materials/analysis tools; I.C., M.C. and F.F. wrote the paper.

Funding: This work was supported by the Universidad de la República, Uruguay and the PEDECIBA Program.

Acknowledgments: We would like to thank Comisión Académica de Posgrado (UdelaR) for granting FF a fellowship to carry on her postgraduate studies. We are also grateful to Dra. Laura Coitiño for kindly allowing us plain access to her lab and all the available resources to perform the computational studies.

Conflicts of Interest: The authors declare no conflict of interest.

\section{References}

1. Spithill, T.W.; Smooker, P.M.; Copeman, D.B. Fasciola gigantica: Epidemiology, control, immunology and molecular biology. In Fasciolosis; Dalton, J., Ed.; CAB International: Wallingford, UK, 1999; pp. 426-525.

2. Mas-Coma, S.; Bargues, M.D.; Valero, M.A. Human fascioliasis infection sources, their diversity, incidence factors, analytical methods and prevention measures. Parasitology 2018, 145, 1665-1699. [CrossRef] [PubMed]

3. Webb, C.M.; Cabada, M.M. Recent developments in the epidemiology, diagnosis, and treatment of Fasciola infection. Curr. Opin. Infect. Dis. 2018, 5, 409-414. [CrossRef] [PubMed]

4. Carmona, C.; Tort, J.F. Fasciolosis in South America: Epidemiology and control challenges. J. Helminthol. 2017, 2, 99-109. [CrossRef] [PubMed]

5. Kelley, J.M.; Elliott, T.P.; Beddoe, T.; Anderson, G.; Skuce, P.; Spithill, T.W. Current Threat of Triclabendazole Resistance in Fasciola hepatica. Trends Parasitol. 2016, 32, 458-469. [CrossRef] [PubMed]

6. Lanusse, C.; Canton, C.; Virkel, G.; Alvarez, L.; Costa-Junior, L.; Lifschitz, A. Strategies to Optimize the Efficacy of Anthelmintic Drugs in Ruminants. Trends Parasitol. 2018, 34, 664-682. [CrossRef]

7. Molina-Hernández, V.; Mulcahy, G.; Pérez, J.; Martínez-Moreno, Á.; Donnelly, S.; O'Neill, S.M. Fasciola hepatica vaccine: We may not be there yet but we're on the right road. Vet. Parasitol. 2015, 208, 101-111. [CrossRef] [PubMed]

8. Dalton, J.P.; O Neill, S.; Stack, C.; Collins, P.; Walshe, A.; Sekiya, M.; Doyle, S.; Mulcahy, G.; Hoyle, D.; Khaznadji, E.; et al. Fasciola hepatica cathepsin L-like proteases: Biology, function, and potential in the development of first generation liver fluke vaccines. Int. J. Parasitol. 2003, 33, 1173-1181. [CrossRef]

9. Cancela, M.; Acosta, D.; Rinaldi, G.; Silva, E.; Durán, R.; Roche, L. A distinctive repertoire of cathepsins is expressed by juvenile invasive Fasciola Hepatica. Biochimie 2008, 10, 1461-1475. [CrossRef]

10. Cancela, M.; Ruétalo, N.; Dell'Oca, N.; da Silva, E.; Smircich, P.; Rinaldi, G. Survey of transcripts expressed by the invasive juvenile stage of the liver fluke Fasciola hepatica. BMC Genomics 2010, 11, 227. [CrossRef]

11. Robinson, M.W.; Tort, J.F.; Lowther, J.; Donnelly, S.M.; Wong, E.; Xu, W. Proteomics and phylogenetic analysis of the cathespin L protease family of the helmith pathogen Fasciola hepatica: Expansion of a repertoire of virulence associated factors. Mol. Cell. Prot. 2008, 6, 1111-1123. [CrossRef]

12. Corvo, I.; Cancela, M.; Cappetta, M.; Pi-Denis, N.; Tort, J.F.; Roche, L. The major cathepsin L secreted by the invasive juvenile Fasciola hepatica prefers proline in the S2 subsite and can cleave collagen. Mol. Biochem. Parasitol. 2009, 167, 41-47. [CrossRef] [PubMed]

13. Cwiklinski, K.; Jewhurst, H.; McVeigh, P.; Barbour, T.; Maule, A.G.; Tort, J. Infection by the Helminth Parasite Fasciola hepatica Requires Rapid Regulation of Metabolic, Virulence, and Invasive Factors to Adjust to Its Mammalian Host. Mol. Cell. Proteomics 2018, 17, 792-809. [CrossRef] [PubMed]

14. Lowther, J.; Robinson, M.W.; Donnelly, S.M.; Xu, W.; Stack, C.M.; Matthews, J.M.; Dalton, J.P. The importance of $\mathrm{pH}$ in regulating the function of the Fasciola hepatica cathepsin L1 cysteine protease. PLoS Negl. Trop. Dis. 2009, 3, e369. [CrossRef] [PubMed] 
15. McVeigh, P.; Maule, A.G.; Dalton, J.P.; Robinson, M.W. Fasciola hepatica virulence-associated cysteine peptidases: A systems biology perspective. Microbes Infect. 2012, 14, 301-310. [CrossRef] [PubMed]

16. Ferraro, F.; Merlino, A.; Dell’oca, N.; Gil, J.; Tort, J.F.; Gonzalez, M.; Cerecetto, H.; Cabrera, M.; Corvo, I. Identification of Chalcones as Fasciola hepatica Cathepsin L Inhibitors Using a Comprehensive Experimental and Computational Approach. PLoS Negl. Trop. Dis. 2016, 10, 0004834. [CrossRef] [PubMed]

17. Hernández-Álvarez, L.; Naranjo Feliciano, D.; Hernández González, J.E.; Soares, R.O.; Barreto Gomes, D.E.; Pascutti, P.G. Insights into the interactions of Fasciola hepatica cathepsin L3 with a substrate and potential novel inhibitors through in silico approaches. PLoS Negl. Trop. Dis. 2015, 9, e0003759. [CrossRef] [PubMed]

18. Abdulla, M.H.; Lim, K.C.; Sajid, M.; McKerrow, J.H.; Caffrey, C.R. Schistosomiasis mansoni: Novel Chemotherapy Using a Cysteine Protease Inhibitor. PLoS Med. 2007, 4, e14. [CrossRef] [PubMed]

19. Vermeire, J.J.; Lantz, L.D.; Caffrey, C.R. Cure of Hookworm Infection with a Cysteine Protease Inhibitor. PLoS Negl. Trop. Dis. 2012, 6, e1680. [CrossRef]

20. Engel, J.C.; Doyle, P.S.; Hsieh, I.; McKerrow, J.H. Cysteine Protease Inhibitors Cure an Experimental Trypanosoma cruzi Infection. J. Exp. Med. 1998, 188, 725-734. [CrossRef]

21. Steverding, D.; Sexton, D.W.; Wang, X.; Gehrke, S.S.; Wagner, G.K.; Caffrey, C.R. Trypanosoma brucei: Chemical evidence that cathepsin $\mathrm{L}$ is essential for survival and a relevant drug target. Int. J. Parasitol. 2012, 42, 481-488. [CrossRef]

22. Sijwali, P.S.; Rosenthal, P.J. Gene disruption confirms a critical role for the cysteine protease falcipain-2 in hemoglobin hydrolysis by Plasmodium falciparum. Proc. Natl. Acad. Sci. USA 2004, 101, 4384-4389. [CrossRef] [PubMed]

23. Liu, J.; Istvan, E.S.; Gluzman, I.Y.; Gross, J.; Goldberg, D.E. Plasmodium falciparum ensures its amino acid supply with multiple acquisition pathways and redundant proteolytic enzyme systems. Proc. Natl. Acad. Sci. USA 2006, 103, 8840-8845. [CrossRef] [PubMed]

24. Li, Y.Y.; Fang, J.; Ao, G.Z. Cathepsin B and L inhibitors: A patent review (2010 present). Expert Opin. Ther. Pat. 2017, 27, 643-656. [CrossRef]

25. Pereira, J.A.; Pessoa, A.M.; Cordeiro, M.N.D.; Fernandes, R.; Prudencio, C.; Noronha, J.P.; Vieira, M.; Cordeiro, M.N.D.S. Quinoxaline, its derivatives and applications: A State of the Art review. Eur. J. Med. Chem. 2015, 97, 664-672. [CrossRef]

26. Ross, F.; Hernández, P.; Porcal, W.; López, G.V.; Cerecetto, H.; González, M.; Basika, T.; Carmona, C.; Fló, M.; Maggioli, G.; et al. Identification of thioredoxin glutathione reductase inhibitors that kill cestode and trematode parasites. PLoS ONE 2012, 7, e35033. [CrossRef] [PubMed]

27. Vicente, E.; Charnaud, S.; Bongard, E.; Villar, R.; Burguete, A.; Solano, B.; Ancizu, S.; Pérez-Silanes, S.; Aldana, I.; Vivas, L.; et al. Synthesis and Antiplasmodial Activity of 3-Furyl and 3-Thienylquinoxaline2-carbonitrile 1,4-Di-N-oxide Derivatives. Molecules 2008, 13, 69-77. [CrossRef] [PubMed]

28. Dos Santos Fernandes, G.F.; Pavan, A.R.; Dos Santos, J.L. Heterocyclic N-oxides-A Promising Class of Agents against Tuberculosis, Malaria and Neglected Tropical Diseases. Curr. Pharm. Des. 2018, 24, 1325-1340. [CrossRef]

29. Bhoj, P.S.; Ingle, R.G.; Goswami, K.; Jena, L.; Wadher, S. Apoptotic impact on Brugia malayi by sulphonamidoquinoxaline: Search for a novel therapeutic rationale. Parasitol. Res. 2018, 117, 1559-1572. [CrossRef]

30. Mcgonigle, L.; Mousley, A.; Marks, N.J.; Brennan, G.P.; Dalton, J.P.; Spithill, T.W.; Day, T.A.; Maule, A.G. The silencing of cysteine proteases in Fasciola hepatica newly excysted juveniles using RNA interference reduces gut penetration. Int. J. Parasitol. 2008, 38, 149-155. [CrossRef]

31. Beckham, S.A.; Piedrafita, D.; Phillips, C.I.; Samarawickrema, N.; Law, R.H.; Smooker, P.M.; Quinsey, N.S.; Irving, J.A.; Greenwood, D.; Verhelst, S.H.L.; et al. A major cathepsin B protease from the liver fluke Fasciola hepatica has atypical active site features and a potential role in the digestive tract of newly excysted juvenile parasites. Int. J. Biochem. Cell Boil. 2009, 41, 1601-1612. [CrossRef]

32. Paveley, R.A.; Bickle, Q.D. Automated imaging and other developments in whole-organism anthelmintic screening. Parasit. Immunol. 2013, 35, 302-313. [CrossRef] [PubMed]

33. Smooker, P.M.; Whisstock, J.C.; Irving, J.A.; Siyaguna, S.; Spithill, T.W.; Pike, R.N. A single amino acid substitution affects substrate specificity in cysteine proteinases from Fasciola hepatica. Protein Sci. 2000, 9, 2567-2572. [CrossRef] [PubMed] 
34. Corvo, I.; Ferraro, F.; Merlino, A.; Zuberbühler, K.; O’Donoghue, A.J.; Pastro, L.; Pi-Denis, N.; Basika, T.; Roche, L.; McKerrow, J.H.; et al. Substrate Specificity of Cysteine Proteases Beyond the S2 Pocket: Mutagenesis and Molecular Dynamics Investigation of Fasciola hepatica Cathepsins L. Front. Mol. Biosci. 2018, 5, 40. [CrossRef] [PubMed]

35. Ganotra, G.K.; Wade, R.C. Prediction of Drug-Target Binding Kinetics by Comparative Binding Energy Analysis. ACS Med. Chem. Lett. 2018, 9, 1134-1139. [CrossRef] [PubMed]

36. Turk, D.; Guncar, G.; Podobnik, M.; Turk, B. Revised definition of substrate binding sites of papain-like cysteine proteases. Biol. Chem. 1998, 379, 137-147. [CrossRef] [PubMed]

37. Ma, S.; Devi-Kesavan, L.S.; Gao, J. Molecular Dynamics Simulations of the Catalytic Pathway of a Cysteine Protease: A Combined QM/MM Study of Human Cathepsin K. J. Am. Chem. Soc. 2007, 129, 13633-13645. [CrossRef] [PubMed]

38. Novinec, M. Computational investigation of conformational variability and allostery in cathepsin $\mathrm{K}$ and other related peptidases. PLoS ONE 2017, 12, e0182387. [CrossRef] [PubMed]

39. Lecaille, F.; Chowdhury, S.; Purisima, E.; Brömme, D.; Lalmanach, G. The S2 subsites of cathepsins K and L and their contribution to collagen degradation. Protein Sci. 2007, 16, 662-670. [CrossRef]

40. Carmona, C.; Dowd, A.J.; Smith, A.M.; Dalton, J.P. Cathepsin L proteinase secreted by Fasciola hepatica in vitro prevents antibody-mediated eosinophil attachment to newly excysted juveniles. Mol. Biochem. Parasitol. 1993, 62, 9-17. [CrossRef]

41. Basch, P. Cultivation of Schistosoma In Vitro. I. Establishment of culture from cercariae and development until pairing. J. Parasitol. 1981, 67, 179-185. [CrossRef]

42. Robinson, M.W.; Corvo, I.; Jones, P.M.; George, A.M.; Padula, M.P.; To, J.; Cancela, M.; Rinaldi, G.; Tort, J.F.; Roche, L.; et al. Collagenolytic Activities of the Major Secreted Cathepsin L Peptidases Involved in the Virulence of the Helminth Pathogen, Fasciola hepatica. PLoS Negl. Trop. Dis. 2011, 5, e1012. [CrossRef] [PubMed]

43. Case, D.A.; Cerutti, D.S.; Cheatham, T.E., III; Darden, T.A.; Duke, R.E.; Giese, T.J.; Gohlke, H.; Goetz, A.W.; Greene, D.; Homeyer, N.; et al. AMBER 16; University of California: San Francisco, CA, USA, 2017.

44. Duan, Y.; Wu, C.; Chowdhury, S.; Lee, M.C.; Xiong, G.; Zhang, W.; Yang, R.; Cieplak, P.; Luo, R.; Lee, T.; et al. A point-charge force field for molecular mechanics simulations of proteins based on condensed-phase quantum mechanical calculations. J. Comput. Chem. 2003, 24, 1999-2012. [CrossRef] [PubMed]

45. Jorgensen, W.L.; Chandrasekhar, J.; Madura, J.D.; Impey, R.W.; Klein, M.L. Comparison of simple potential functions for simulating liquid water. J. Chem. Phys. 1983, 79, 926-935. [CrossRef]

46. Essmann, U.; Perera, L.; Berkowitz, M.L.; Darden, T.; Lee, H.; Pedersen, L. A smooth particle mesh Ewald method. J. Chem. Phys. 1995, 103, 8577-8593. [CrossRef]

47. Berendsen, H.J.C.; Postma, J.P.M.; Van Gunsteren, W.F.; Haak, A.R.H.J.; Haak, J.R. Molecular dynamics with coupling to an external bath. J. Chem. Phys. 1984, 81, 3584-3690. [CrossRef]

48. Pastor, R.W.; Brooks, B.R.; Szabo, A. An analysis of the accuracy of Langevin and molecular dynamics algorithms. Mol. Phys. 1988, 65, 1409-1419. [CrossRef]

49. Ryekaert, J.P.; Ciecotti, G.; Berendsen, H.J.C. Numerical-integration of cartesian equations of motion of a system with constraints-molecular-dynamics of $N$-alkanes. J. Comput. Chem. 1997, 23, 327-341. [CrossRef]

50. Shao, J.; Tanner, S.W.; Thomson, N.; Cheatham, T.E. Clustering Molecular Dynamics Trajectories: 1. Characterizing the Performance of Different Clustering Algorithms. J. Chem. Theory Comput. 2007, 3, 2312-2334. [CrossRef]

51. Humphrey, W.; Dalke, A.; Schulten, K. VMD-Visual Molecular Dynamics. J. Mol. Graph. 1996, 14, 33-38. [CrossRef] [PubMed]

52. Chai, J.D.; Head-Gordon, M. Long-range corrected hybrid density fuctionals with dumped atom-atom dispersion corrections. J. Chem. Phys. 2008, 10, 6615-6620. [CrossRef]

53. Krishnan, R.; Binkley, J.S.; Seeger, R.; Pople, J.A. Self-Consistent Molecular Orbital Methods. XX. A Basis set for correlated wave-functions. J. Chem. Phys. 1980, 72, 650-654. [CrossRef]

54. Cances, M.T.; Mennucci, B.; Tomasi, J. A new integral equation formalism for the polarizable continuum model: Theoretical background and applications to isotropic and anisotropics dielectrics. J. Chem. Phys. 1997, 107, 3032-3041. [CrossRef]

55. Frisch, M.J.; Trucks, G.W.; Schlegel, H.B.; Scuseria, G.E.; Robb, M.A.; Cheeseman, J.R.; Scalmani, G.; Barone, V.; Petersson, G.A.; Nakatsuji, H.X.; et al. Gaussian 09; Revision A.02; Gaussian Inc.: Wallingford, CT, USA, 2009. 
56. Morris, G.M.; Huey, R.; Lindstrom, W.; Sanner, M.F.; Belew, R.K.; Goodsell, D.S.; Olson, A.J. AutoDock4 and AutoDockTools4: Automated Docking with Selective Receptor Flexibility. J. Comput. Chem. 2009, 30, 2785-2791. [CrossRef]

57. Wang, J.M.; Wolf, R.M.; Caldwell, J.W.; Kollman, P.A.; Case, D.A. Development and testing of a general amber force field. J. Comput. Chem. 2004, 25, 1157-1174. [CrossRef] [PubMed]

58. Breneman, C.M.; Wiberg, K.B. Determining atom-centered monopoles from molecular electrostatics potentials-The need for high sampling density in formamide conformational analysis. J. Comput. Chem. 1990, 11, 361-373. [CrossRef]

Sample Availability: Samples of the compounds are not available from the authors.

(C) 2019 by the authors. Licensee MDPI, Basel, Switzerland. This article is an open access article distributed under the terms and conditions of the Creative Commons Attribution (CC BY) license (http://creativecommons.org/licenses/by/4.0/). 